\title{
Determining available strategies for prevention and therapy: Exploring COVID-19 from the perspective of ACE2 (Review)
}

\author{
LIYANG CAI $^{1 *}$, XI GUO $^{2 *}$, YUCHEN CAO $^{1}$, PEIXI YING $^{1}$, LIBING HONG $^{1}$, \\ YUXI ZHANG ${ }^{1}$, GUOGUO $\mathrm{YI}^{3}$ and $\mathrm{MIN} \mathrm{FU}^{4}$ \\ ${ }^{1}$ The Second Clinical School, ${ }^{2}$ Medical College of Rehabilitation, Southern Medical University, Guangzhou, \\ Guangdong 510515; ${ }^{3}$ Department of Ophthalmology, The Sixth Affiliated Hospital of Sun-Yat-Sen University, \\ Guangzhou, Guangdong 510655; ${ }^{4}$ Department of Ophthalmology, Zhujiang Hospital of \\ Southern Medical University, Guangzhou, Guangdong 510282, P.R. China
}

Received September 3, 2020; Accepted December 7, 2020

DOI: $10.3892 / \mathrm{ijmm} .2021 .4876$

\begin{abstract}
Coronavirus disease 2019 (COVID-19) is an acute infectious pneumonia caused by a novel type of coronavirus infection. There are currently no clinically available specific drugs for the treatment of this virus. The process of host invasion is the key to viral infection, and it is a mechanism that needs to be considered when exploring antiviral drugs. At present, studies have confirmed that angiotensin-converting enzyme II (ACE2) is the main functional receptor through which severe acute respiratory syndrome coronavirus
\end{abstract}

Correspondence to: Dr Guoguo Yi, Department of Ophthalmology, The Sixth Affiliated Hospital of Sun-Yat-Sen University, 26 Erheng Road, Yuancun, Tianhe, Guangzhou, Guangdong 510655, P.R. China E-mail: yigg@mail.sysu.edu.cn

Dr Min Fu, Department of Ophthalmology, Zhujiang Hospital of Southern Medical University, 253 Industrial Avenue Central, Zhuhai, Guangzhou, Guangdong 510282, P.R. China

E-mail:min_fu1212@163.com

*Contributed equally

Abbreviations: ACE2, angiotensin converting enzyme 2; ACEIs, ACE inhibitors; AngI, angiotensin I; AngII, angiotensin II; ARB, angiotensin II receptor blocker; ARDS, acute respiratory distress syndrome; AT1R, angiotensin II type 1 receptor; CKD, chronic kidney disease; COVID-19, Coronavirus disease 2019; CQ, chloroquine phosphate; CRP, C-reactive protein; ECG, electrocardiogram; GRFT, griffithsin; hrsACE2, human recombinant soluble ACE2; HTA, host targeting agent; KO, knockout; mAbs, monoclonal antibodies; mGRFT, GRFT monomer; PPAR- $\gamma$, peroxisome proliferator-activated receptor- $\gamma$; RAAS, renin-angiotensin-aldosterone system; RAS, renin-angiotensin system; RBD, receptor binding domain; rhACE2, recombinant human angiotensin converting enzyme 2 ; $S$ protein, spike protein; SARS-CoV-2, severe acute respiratory syndrome coronavirus type 2; SRBD, S protein receptor-binding region; Th17, T helper cell 17; TMPRSS2, transmembrane serine protease 2 ; WT, wild-type

Key words: SARS-CoV-2, COVID-19, spike protein, ACE2, RAS, therapeutics, mechanism
(SARS-CoV-2) invades host cells. Therefore, a number of studies have focused on this field. However, as ACE2 may play a dual role in mediating susceptibility and immunity to SARS-CoV-2 infection, the role of ACE2 in viral infection is controversial. Beginning with the physiological function of ACE2, the present review article summarizes the influence of the ACE2 content on the susceptibility to the virus and acute lung injury. Drug mechanisms were taken as the starting point, combined with the results of clinical trials, specifically elaborating upon and analyzing the efficacy of several ACE2-centered therapeutic drugs and their potential effects. In addition, the current status of ACE2 as a targeted therapy for COVID-19 is discussed in order to provide new insight into the clinical prevention and treatment of COVID-19.

\section{Contents}

1. Introduction

2. Angiotensin-converting enzyme 2

3. ACE2 has potential for use in the treatment of COVID-19

4. ACE2-centered drug therapy

5. Conclusions and future perspectives: Potentials and pitfalls

\section{Introduction}

At the end of 2019, the first confirmed case of Coronavirus disease 2019 (COVID-19) was reported, and the virus rapidly spread to hundreds of countries worldwide (1). High-throughput sequencing identified the COVID-19 pathogen as a novel $\beta$ coronavirus (2), and the International Committee for Classification of Viruses named it severe acute respiratory syndrome coronavirus type 2 (SARS-CoV-2). Epidemiological studies have demonstrated that COVID-19 infects individuals of all ages (3), with the elderly and patients with underlying comorbidities being at a higher risk of adverse clinical outcomes and a poor prognosis $(3,4)$. Sequence analysis has identified that SARS-CoV-2 and 2003 SARS-CoV share approximately $80 \%$ nucleotide identity (5). However, compared with SARS-CoV, SARS-CoV-2 is more infectious than SARS-CoV, which has caused >120 infections worldwide; 
since however, only some patients exhibit a severity of symptoms similar to those of SARS-CoV infection, its virulence seems lower. Similar to SARS-CoV, according to reported cases, SARS-CoV-2 is primarily transmitted through respiratory droplets and direct contact $(3,6)$, both of which can cause acute and highly fatal pneumonia (7). Unlike SARS-CoV, SARS-CoV-2-infected patients rarely exhibit prominent upper respiratory signs and symptoms. At the time of consultation, the majority of infected patients present with a dry cough (83-99\%) and dyspnea (59.4-82\%), and $\mathrm{X}$-rays have revealed bilateral ground-glass shadows $(1,8)$. In the most severe cases, the characteristic symptom is respiratory distress $(\sim 55 \%)$. In addition, SARS-CoV-2 needs to bind to its receptor through the spike protein (S protein) on the surface of the virus to enter the host cell (2).

The renin-angiotensin system (RAS) maintains blood pressure homeostasis and water-salt balance (9). The dynamic balance of RAS is essential for the physiological and pathological regulation of various organs, including the heart, kidneys and lungs (9). Angiotensin-converting enzyme 2 (ACE2) is a key factor for RAS to negatively regulate blood pressure and is essential for maintaining the dynamic balance of RAS $(10,11)$. A previous study found that ACE2 is a functional receptor for invasion by the novel coronavirus (SARS-CoV-2); it interacts with the viral spike glycoprotein (S protein) receptor binding domain to mediate viral invasion of host cells (12). Therefore, during the SARS coronavirus infection process, ACE2 is essential for the virus to enter host cells. Using HeLa cells expressing human (2), Chinese horseshoe bat, civet cat and pig ACE2 protein for computational modeling and viral infection experiments (13), the experimental results demonstrated that the affinity of SARS-CoV-2 for ACE2 was 10-fold higher than that of SARS-CoV, which is consistent with the high infection efficiency of SARS-CoV-2 (14). In addition, current research results have indicated that when the ACE2 content is very high, it can attenuate viral invasion and reduce acute lung injury damage, while at the same time enhancing viral replication ability and susceptibility. By contrast, when the ACE2 content is low, it hinders the ability of the virus to replicate, but to a certain extent, when the ACE2 content is too low, it increases the levels of angiotensin II (AngII), which plays a role in promoting inflammation and fibrosis, inducing multiple organ damage. These findings indicate that ACE2 may be critical to the progression and prognosis of human infection with SARS-CoV-2.

Since the emergence of this novel virus, there are currently no clinically specific treatments available for this virus, and symptomatic treatment is the main focus. Therefore, the rapid search and development of specific drugs to inhibit SARS-CoV-2 infection has become a priority. As a key receptor in the process of viral invasion, existing research results suggest that there is great potential for treating new coronary pneumonia by adjusting the levels of ACE2. Therefore, the present review article begins by discussing the physiological function of ACE2 and summarizing the impact of the ACE2 content on viral susceptibility and acute lung injury. Subsequently, from the perspective of drug mechanisms, combined with the results of clinical trials, several ACE2-centric treatments are specifically elaborated and analyzed. The drug efficacy and areas that need improvement are reviewed. The research discussed herein, to a certain extent, may aid medical workers to correctly understand the role of ACE2 in the disease process, understand the complex effects of the substance in viral infections and acute lung injury, and use ACE2-centered drug therapy in a prudent and standard manner. At the same time, several therapies and mechanisms related to ACE2 listed in this review article can also provide researchers with certain insight for the development of novel drugs.

\section{Angiotensin-converting enzyme 2}

ACE is a type I transmembrane glycoprotein with a single extracellular catalytic domain. It plays an important regulatory role in the RAS and converting inactive angiotensin I (AngI) into AngII, which regulates vasoconstriction. AngII is the core effector molecule of the RAS system and mediates a number of biological responses through angiotensin receptors (AT1 and AT2).

ACE2 was the first human angiotensin converting enzyme homolog discovered in $2000(15,16)$ and is a zinc metalloproteinase. Its coding gene is located on the $\mathrm{X}$ chromosome and belongs to the family of type 1 transmembrane proteins. Its structure includes a signal peptide, a transmembrane domain and a metalloproteinase active site, containing a zinc binding domain of HEXXH. As a monocarboxy peptidase, unlike its homolog ACE, which is a dipeptidase, ACE2 is not antagonized by ACE inhibitors (ACEIs) (17). ACE contains two active catalytic domains, while ACE2 has a single catalytic domain with $42 \%$ of the same residues $(18,19)$ that not only degrades AngI to produce nonapeptide Ang1-9, but also cleaves AngII into Ang1-7 polypeptides (20) (Fig. 1). While protecting the heart, relaxing blood vessels, and exerting anti-growth and anti-proliferative effects, it also enhances the activity of bradykinin. ACE2/ACE and AngII/Ang1-7 in the human body exist in a dynamic balance that regulates several important physiological functions (21).

The expression of ACE2 exhibits high tissue specificity (22). The primary organs expressing ACE2 include the heart, brain, oral cavity and nasal mucosa, nasopharynx, kidney, stomach, small intestine, colon, skin, lymph nodes, thymus, bone marrow, spleen, liver and blood vessels, which are targets of the SARS-CoV-2 virus $(23,24)$. In addition, alveolar epithelial cells have been regarded as the most important cell type for ACE2 expression (25). Accordingly, it is hypothesized that SARS-CoV-2 may bind to RAS through ACE2.

Yan et al (25) at West Lake University, examined the composite structure of the new coronavirus spike $\mathrm{S}$ protein and ACE2 receptor, observing that the novel coronavirus binds to the human cell receptor ACE2 through the S protein. Coronavirus binding to the ACE2 receptor induces a decrease in ACE2 levels, and the RAS system becomes activated, leading to disease. Based on this consistent pathogenesis, improving ACE2 and inhibiting the RAS system may represent important options for the treatment of pneumonia caused by the novel coronavirus (14).

\section{ACE2 has potential for use in the treatment of COVID-19}

ACE2 is a key receptor in the invasion of host cells by $S A R S-C o V 2$. Studies have confirmed that the key functional receptor for SARS-CoV2 to enter cells is ACE2 $(15,16)$. The process occurs as follows: The $\mathrm{S}$ protein on the surface of the 


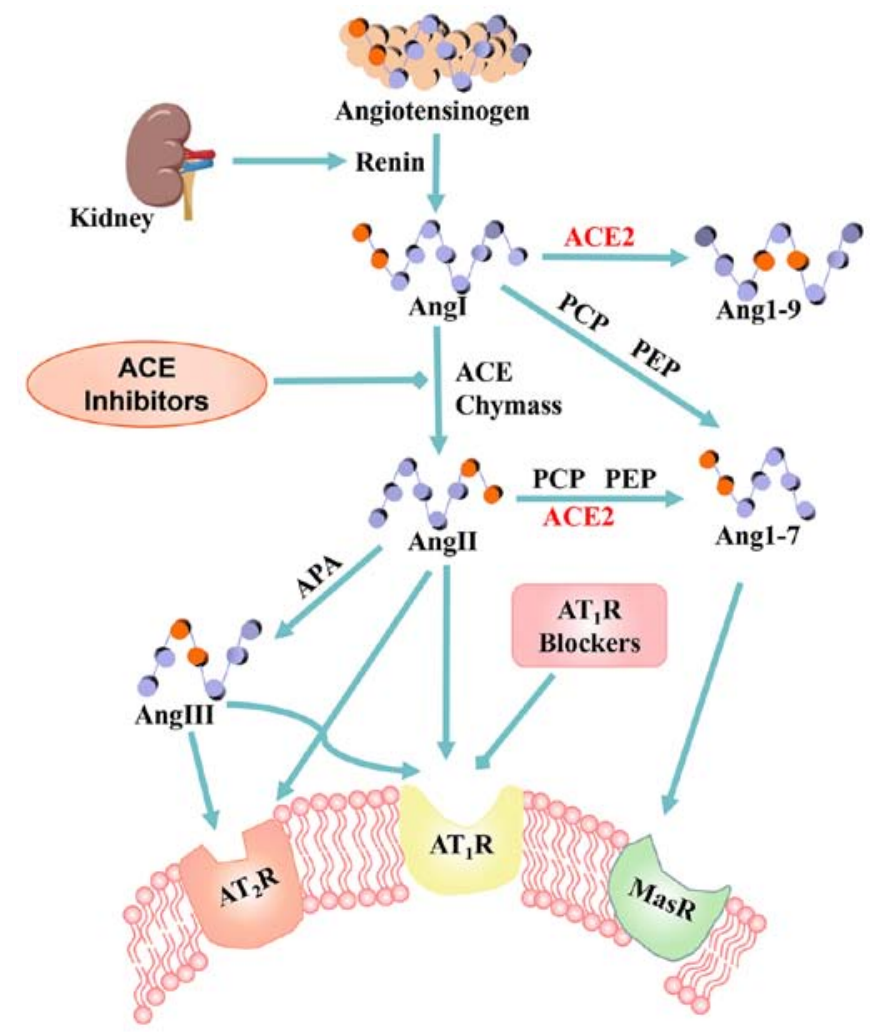

Figure 1. Enzymatic cascade of the renin-angiotensin system (RAS) and the key receptor systems. The RAS cascade showing the angiotensin peptide metabolic pathway. Angiotensinogen, as the starting substrate, is cleaved by renin to AngI. AngI is cleaved by ACE to AngII, which is cleaved by ACE2 to Ang(1-7). AngII acts on AT1 and AT2 receptors. Ang(1-7) acts on Mas receptors and counterbalances the AngII/AngII AT1R actions. RAS, renin-angiotensin system; AngI, angiotensin I; AngII, angiotensin II; ACE, angiotensin-converting enzyme; AT1R, angiotensin II type 1 receptor; APA, aminopeptidase A PCP, prolyl carboxypeptidase; PEP, proline endopeptidase.

virus that is responsible for mediating receptor recognition and cell membrane fusion is cleaved into the S1 and S2 subunits during development. The $\mathrm{S} 1$ subunit contains a receptor binding domain that interacts with ACE2. When bound, another cleavage site on $\mathrm{S} 2$ is exposed and cut by the host's protease (17). This process is of vital importance to the successful invasion of the virus. Following the entry of the virus, the ACE2 protein is downregulated, dysregulating the ACE-AngII/angiotensin II type 1 receptor (AT1R) axis and the ACE2-Ang1-7/Mas axis, and AngII levels are relatively/absolutely increased, which overstimulate AT1R, increase lung capillary permeability and induce acute lung failure. This provides a molecular explanation for acute respiratory distress syndrome (ARDS), the death mechanism of the coronavirus infection (26). In response to this mechanism, potential treatment strategies include blocking the receptor binding domain (RBD) of the viral S protein or the functional receptor of ACE2 to prevent the binding of human ACE2 and SARS-CoV-2. In addition to this blocking strategy, other possible treatment options may include increasing the ACE2 levels and the topical use of ACE2-derived peptides, small molecule inhibitors, ACE2 antibodies, or single-chain antibody fragments against ACE2 (Fig. 2).

ACE2 and COVID-19. According to clinical diagnosis and treatment, the main symptoms of patients infected with
COVID-19 include high blood pressure, diarrhea and damage to multiple organs, including the heart, kidneys and testes (27). These diffuse COVID-19 manifestations may be related to infection and RAS overreaction. Therefore, it was hypothesized that, as an important negative feedback regulator of RAS, ACE2 represents a reasonable target for the prevention and treatment of COVID-19. Fortunately, current research indicates that ACE2 has good potential for use in the treatment of patients with ARDS, cardiovascular disease, gastrointestinal malnutrition and other viral-related symptoms (28). This is discussed below.

i) ACE2 and acute respiratory distress syndrome: ARDS is characterized by severe hypoxemia and extreme difficulty in breathing, which represents the main cause of mortality in patients with COVID-19. As mentioned above, imbalance in the ACE-AngII/AT1R axis in the classic RAS pathway increases the permeability of lung capillaries and the influx of calcium ions, which indirectly promotes the occurrence of acute lung failure. ACE2 can protect patients from lung injury by regulating this process.

Previous studies performing animal experiments have demonstrated that compared with normal wild-type (WT) control mice, ACE2 knockout (KO) mice exhibit a very severe ARDS pathology, including enhanced vascular permeability, severe pulmonary edema and moderate accumulation of sex-specific granulocytes, deterioration of lung function, etc. $(9,29)$. These observations suggest that the balance in the ACE2/ACE content is the key to lung injury/protection during these inflammatory factor storms. Further analyses have indicated that the artificial injection of the AT1R blocker, angiotensin II receptor blocker (ARB), induces the expression of ACE2, Ang 1-7 and Mas, leading to a decrease in pro-inflammatory cytokine levels and an increase in the levels of the anti-inflammatory cytokine, interleukin (IL)-10 (29). This protective effect of ACE2 may reduce AGII by decomposing it into AG (1-7). In another study using mice, SARS-CoV infection and its $\mathrm{S}$ protein downregulated the expression of ACE2 (30). Clinical observations and experiments at this stage have also yielded similar results. A retrospective study found that in 300 patients with COVID-19-induced acute pneumonia, multiple organ failure caused by an inflammatory cytokine storm was the main cause of mortality (31). Researchers speculate that when the immune system is activated in response to SARS-CoV2 infection, the existing $\mathrm{T}$ helper cell 17 (Th17)/Treg functional cells and immune cells secrete a large number of pro-inflammatory cytokines, and this hyperactivity leads to an imbalance in cytokine content. This imbalance, coupled with the loss of ACE2 due to the invasion of COVID-19, ultimately leads to tissue and systemic inflammation (32). Following the injection of recombinant human ACE2 (rhACE2), an artificially created ACE2 protein, pathological damage and inflammation in the lung were improved (18). A series of studies in Austria have proven that in acute lung injury caused by SARS and certain influenza viruses, ACE2 buffers the lung fibrosis and lung injury caused by the excessive activation of RAS to a certain extent (33). Moreover, levels of plasma AngII in patients with COVID-19 are significantly increased, which exhibits a linear correlation with viral titer and the degree of lung injury, suggesting that SARS-CoV2 may cause acute lung injury by 


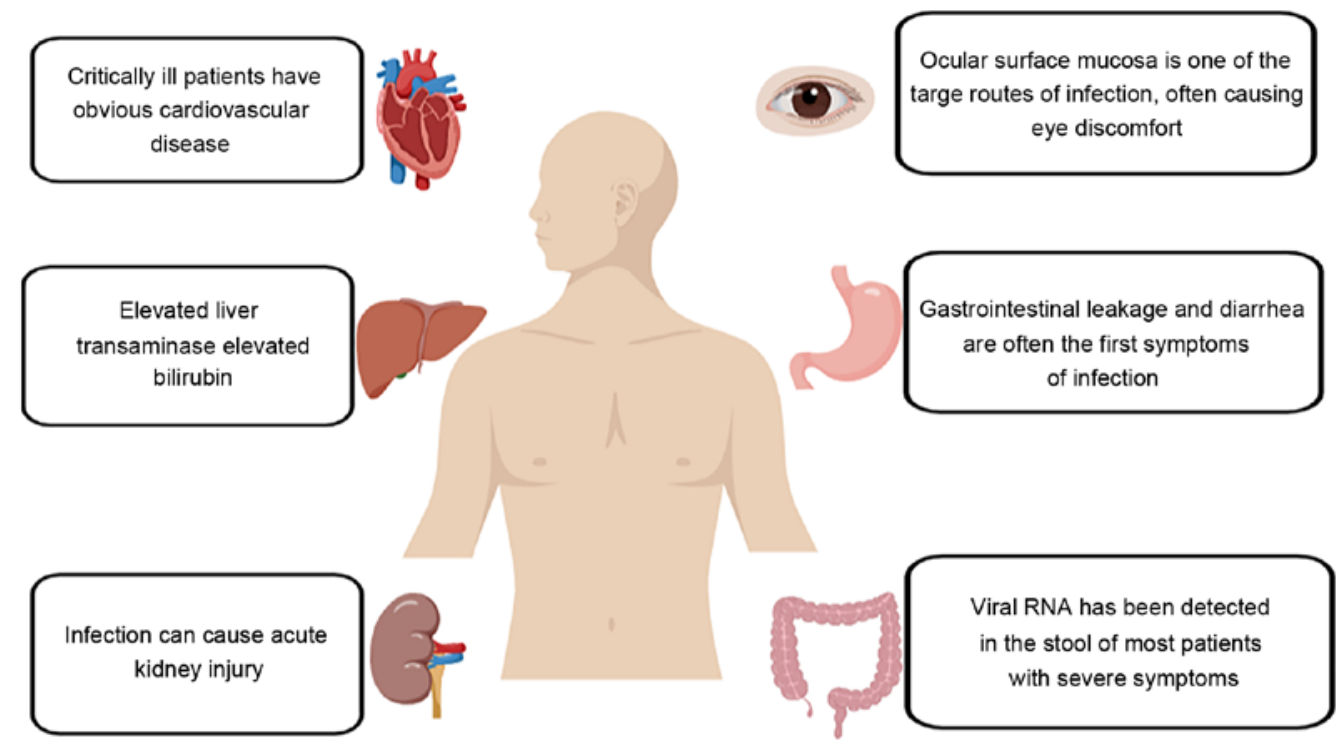

Figure 2. Damage to multiple organs caused by the virus. According to clinical diagnosis and treatment observations, the virus invasion can cause damage to multiple systems and organs, resulting in diffuse COVID-19 disease; therapies surrounding ACE2 have exhibited good therapeutic potential in the treatment of a number of diseases. ACE, angiotensin-converting enzyme.

reducing the expression levels of ACE2 and disrupting the ACE/ACE2 balance.

Based on the above-mentioned studies, it can be concluded that in patients with COVID-19, ACE2 represents a potential reasonable target for the prevention and treatment of acute respiratory distress syndrome. Relying on the human body's own RAS mechanisms to increase the ACE2 content is expected to provide positive results for the treatment of patients with ARDS.

ii) ACE2 and cardiovascular disease in patients with COVID-19: In addition to acute pneumonia, the critical illnesses caused by COVID-19 also includes cardiovascular disease. A previous study demonstrated that in autopsy heart tissues from 20 patients who had succumbed to SARS-CoV, 7 heart samples exhibited obvious cardiovascular lesions characterized by increased myocardial fibrosis, inflammation, and decreased myocardial ACE2 expression (34). These patients were also more severely ill and exhibited a higher mortality rate. A similar phenomenon is observed in SARS-CoV2 patients: Individuals with pre-existing diseases, such as hypertension and heart disease, have an increased specific risk of COVID-19 infection, and in patients with COVID-19, acute myocardial injury is frequent. Other abnormal phenomena have also been observed in the laboratory, including increased D-dimer and continuously increased inflammatory cytokine levels throughout the clinical course $(35,36)$. These phenomena all indicate that the cardiovascular system is continuously experiencing inflammation in patients with COVID-19.

As a regulator of the RAS system, ACE2 effectively relieves a number of cardiovascular diseases, including hypertension and coronary heart disease. As early as the end of the last century, drugs for the treatment of cardiovascular disease appeared that were developed based on the ACE2-Ang(1-7)/Mas axis, and they have currently become classic prescription drugs. It has been demonstrated that in a rat model of myocardial infarction, compared with the myocardial tissue that survived 3 days following infarction, the infarct and the peri-infarct area exhibited an increased expression of ACE2 (37). As ACE2 exerts a protective effect on lung and heart tissue damage, it is hypothesized that hypertensive patients with COVID-19 are more likely to develop complications and severe cases. A large number of observations have also confirmed this point. The severity of COVID-19 infection in patients with hypertension is indeed greater. In addition, compared with non-severe cases, severe cases of COVID-19 exhibit relatively higher systolic blood pressure (145 mmHg vs. $122 \mathrm{mmHg}$ ) (38). This phenomenon indicates that SARS-CoV-2 deprives tissues of ACE2, leading to a marked decrease in ACE2 levels that indirectly lead to the occurrence of hypertension.

At present, studies have suggested that the use of ARB drugs in patients with COVID-19 may help to improve the patient's condition or even decrease their risk of mortality. A study completed in 2017 revealed that ARB effectively blocked AT1R, antagonizing the main AngII actions and exhibiting protective pleiotropic effects against hypertension and cardiovascular inflammation, fibrosis and thrombosis (39). The data available from $>20$ clinical trials currently in progress (e.g., NCT04312009, NCT04311177, NCT04318418) indicate that ARB decreases the viral load, prevents peripheral $\mathrm{T}$ cell depletion and reduces plasma IL-6 levels, C-reactive protein (CRP) and procalcitonin levels (40). However, this therapy has been mainly shown to be effective in subjects with hyperinflammatory periods or previous hypertension. The European Society of Cardiology and the American Heart Association advise against terminating these maintenance treatments for patients with COVID-19, particularly in the presence of high blood pressure or heart failure (41). However, at present, due to the lack of clinical statistics with a larger sample size, a large controversy remains as to whether ARB drugs should be used in the treatment of patients with COVID-19. Further research is required to determine whether the long-term use of these therapies will cause different consequences in specific tissues.

iii) ACE2, enteric malnutrition and disease progression in patients with COVID-19: As regards the clinical symptoms 
of the novel coronary pneumonia, gastrointestinal symptoms are often the first observed or accompanying symptoms. ACE2 is most commonly expressed in intestinal epithelial cells, spreading over the surface of the entire gastrointestinal lumen, making the intestine a secondary site of SARS-CoV-2 infection. Gastrointestinal leakage in experimental models of human diseases are improved and worsened by the increased and decreased ACE2 levels, respectively $(42,43)$. A study on 811 patients with COVID-19 with gastrointestinal discomfort and diarrhea found that gastrointestinal symptoms may appear earlier than symptoms of lung infection (44). In addition, the majority of the currently known coronaviruses affect the integrity of the gastrointestinal blood barrier and cause intestinal dysbiosis, bacteremia and systemic inflammation. The development of gastrointestinal leakage and enteral malnutrition is closely related to the excessive activation of the ACE/AngII/AT1R axis caused by the loss of ACE2 $(45,46)$. Fecal viral RNA has been detected in up to $70 \%$ of patients with gastrointestinal virus shedding and a more aggressive clinical course $(47,48)$.

In addition to the direct impact of the virus on the microbiome, diseases such as diabetes and lung diseases, also have an adverse effect on the gut microbiome, and SARS-CoV-2 infection may increase disease severity (49-51). In animal models and humans, AngII-dependent hypertension is associated with enteral malnutrition, increased intestinal leakage and pathological changes in the intestinal wall $(52,53)$. The destruction of ACE2 in the biomedical model indicates that intestinal malnutrition is very common and that this change in the microbial profile can alter the systemic pathway and exacerbate diabetes and hypertension (26).

Therefore, it can be concluded that the decrease in intestinal ACE2 expression caused by SARS-CoV-2 infection may similarly reduce circulating angiogenic cells and damage the integrity of endothelium and intestinal epithelium, leading to malnutrition. However, further investigations are warranted to verify whether this phenomenon is a direct or indirect effect of viral infection. If further research confirms the existence of viruses through intestinal infections, fecal bacteria transplantation, probiotic therapy, etc., can regulate the intestinal microecology to indirectly adjust the ACE/ACE2 balance, which has potential for the treatment of patients with COVID-19.

Potential risks. It has to be acknowledged that ACE2 has great potential for the treatment of patients with COVID-19. However, since the current considerations basically stem from theoretical derivation and small basic experiments, there is still a lack of convincing clinical data. Thus, during the pandemic of the novel coronary pneumonia, the use of ACE2 and its related inhibitors for the treatment of patients with COVID-19 still conveys potential risks to a certain extent. This primarily manifests in two aspects. First, in terms of dose, the levels of ACE2 have complexity in novel coronary infection (Fig. 3). Second, in terms of therapeutic efficacy, the use of ACE2 and its related inhibitors may promote infection in patients with complications, such as hypertension and cardiovascular disease (54-56). This is discussed below.

i) The content of ACE2 is complex in SARS-CoV-2 infections: The interaction between the SARS-CoV-2 virus and
ACE2 is considered a potential feature of its infectivity (26); thus, there may be approaches which may be used to intervene in this process to resist SARS-CoV-2 infection, such as delivering excess soluble ACE2 or inhibiting SARS-CoV-2 virus interaction with angiotensin-converting enzyme 2.

Generally, it is considered that excessive ACE2 levels, particularly soluble forms of ACE2, may slow viral entry and spread. In addition, this may not only prevent lung injury by neutralizing the virus, but also release cellular ACE2 and enhance its activity. As a protective factor that inhibits lung injury and multiple organ failure of the RAS classic axis, its expression should be increased, but ACE2 is also a receptor for viral infection. It has been demonstrated that ACE2 promotes the replication of SARS-CoV (57). The expression levels of ACE2 in cells are positively associated with susceptibility to the SARS-CoV S protein. After the host cells are infected with ACE2, viral replication capacity increases (58). Moreover, the affinity of SARS-CoV-2 for ACE2 is 10- to 20-fold greater than that of SARS-CoV (13); thus, excessive levels of ACE2 may increase the chance of infection with SARS-CoV-2.

A lack of ACE2 has both advantages and disadvantages. For patients who have been infected, a lack of ACE2 leads to increased levels of AngII, which acts more on the target organ AT1R to play a pro-inflammatory, pro-fibrotic and other roles, causing target organ lesions, which in turn induces multiple organ damage (24). In addition, ACE2 deficiency also exerts a positive effect. Following SARS-CoV infection in mice, the levels of ACE2 in the lungs of mice significantly decrease, and the levels of SARS virus infection in the lungs also significantly decreased (26). ACE2 KO mice are more resistant to SARS-CoV infection, and ACE2 inhibitors also prevent SARS-CoV replication $(26,58,59)$.

However, it has been demonstrated that the expression of ACE2 in intestinal epithelial cells is positively associated with viral entry, release and cellular immunity genes, but negatively associated with viral transcription, protein translation, humoral immunity, phagocytosis and complement activation (60). This suggests that ACE2 may play a dual role in mediating susceptibility and immunity to SARS-CoV-2 infection; thus, it needs to be used with caution.

ii) ACE2 may promote infection in patients with complications, such as hypertension and cardiovascular disease: Recent evidence has indicated that patients with diseases, such as diabetes, hypertension and obesity (61), have the highest prevalence of novel coronary pneumonia infections and are at a risk of mortality (62). While ACE2 inhibitors and angiotensin receptor blockers are basic drugs for the treatment of hypertension, heart disease and chronic kidney disease, ACE2 is an important functional receptor for SARS-CoV-2 infected hosts. A number of patients and physicians are therefore concerned that the use of renin-angiotensin-aldosterone system (RAAS) inhibitors will increase the risk of viral infection in these patients.

de Abajo et al compared the current use of RAAS inhibitors with other anti-hypertensive drugs for some confirmed admissions (63). The results demonstrated that compared with the use of other anti-hypertensive drugs, the use of RAAS inhibitors was not associated with an increased risk of infection requiring admission, but was associated with an increased risk of severe complications requiring intensive care. 

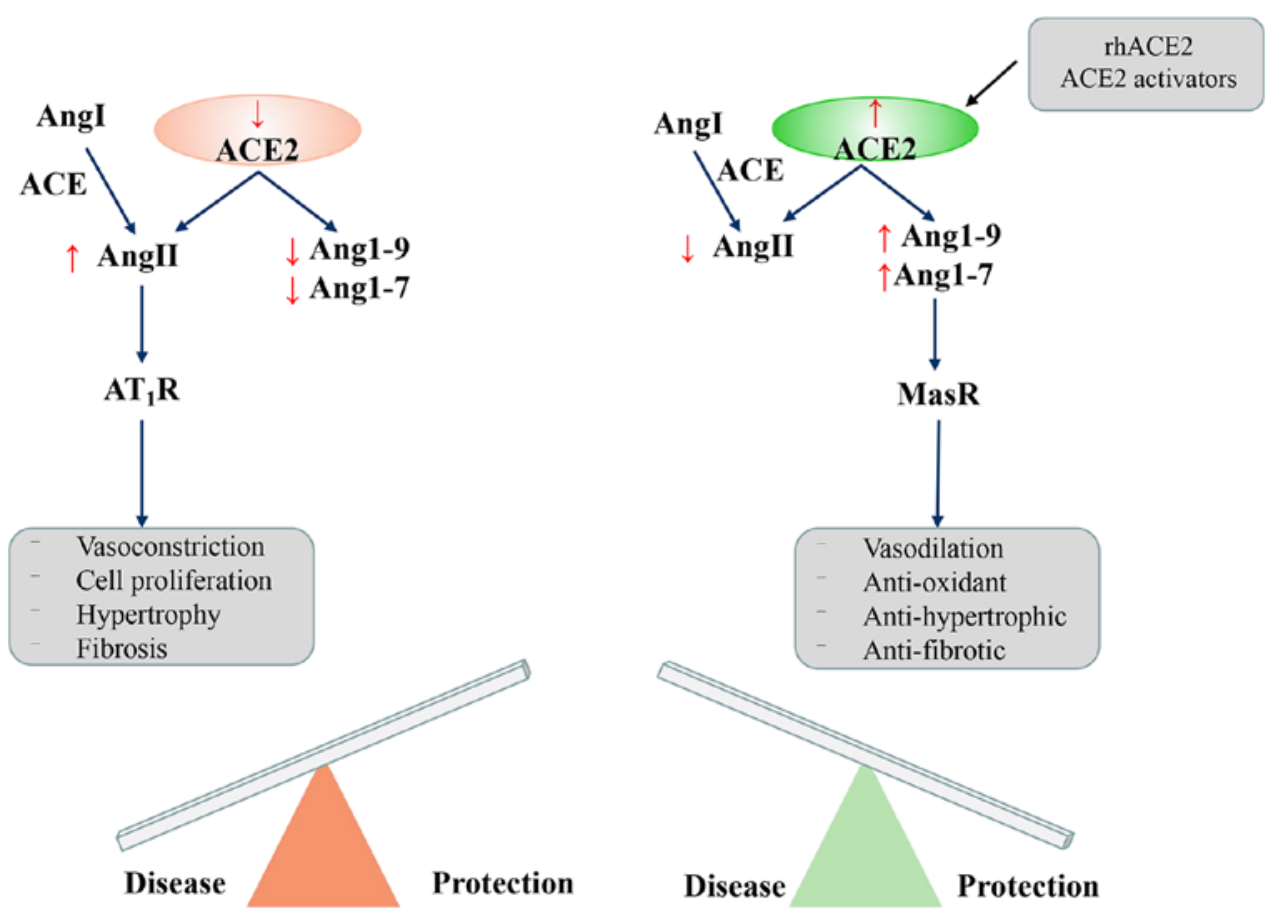

Figure 3. Content of ACE2 is complex in SARS-CoV-2 infections. Decreased ACE2 shifts the balance in the RAS to the AngII/AT1R axis, resulting in disease progression. Increased ACE2 (by rhACE2, gene delivery, or ACE2 activators) shifts the balance to the Ang(1-7)/MasR axis, leading to protection from disease. ACE, angiotensin-converting enzyme; AT1R, angiotensin II type 1 receptor; AngI, angiotensin I; AngII, angiotensin II; rhACE2, recombinant human ACE2.

In contrast to the above-mentioned findings, de Abajo et al found an interesting and potentially clinically significant result in their study. They observed that the administration of RAAS inhibitors reduced the risk of adverse outcomes in diabetic patients with new-onset coronary pneumonia by almost half compared with other anti-hypertensive drugs (63). Other studies have also suggested that compared with other anti-hypertensive drugs, the use of RAAS inhibitors may exert a protective effect on complications and mortality in patients with the novel coronary pneumonia, although these studies were not limited to diabetic patients $(64,65)$.

Several studies with mixed conclusions (63-67) have demonstrated that there is currently no clear evidence that RAAS inhibitors increase the risk of infection in patients with the new-onset coronary pneumonia. However, there is also no strong evidence to support that once infected, the use of RAAS inhibitors increases the risk of infection or the severity of complications compared to treatment with other antihypertensive agents. The results of some studies even obtained opposite findings. However, this potentially important finding needs to be confirmed in large randomized controlled trials $(65,65)$.

In summary, although ACE2 has great potential for use in the treatment of the novel coronavirus pneumonia, there are indeed some potential risks surrounding the use of ACE2 and its related inhibitors for treatment. In line with the humanitarian principle of the supremacy of patient interests, when conducting clinical trials and formulating diagnostic and treatment strategies, it is necessary to understand the mechanisms of action of the drugs in detail and their therapeutic effects as much as possible in order to select the diagnostic and treatment strategy with the optimal efficacy by synthesizing various factors. Thus, a general understanding of the existing diagnostic and treatment strategies is required.

\section{ACE2-centered drug therapy}

The above-mentioned findings suggest that ACE2 has great potential for use in the treatment of COVID-19. As a whole, although there are some potential treatment risks. However, if used reasonably, ACE2 may become a reasonable target for the prevention and treatment of COVID-19. At present, there are a number of diagnostic and treatment programs available for ACE2, which can be divided into 2 categories. One is based on the process of virus S protein that needs to bind ACE2 to invade cells, targeting $S$ protein-ACE2 interactions to inhibit viral invasion and including drugs, such as arbidol, chloroquine, etc. The mechanism of action of another class of drugs is to regulate the ACE2 content for the prevention and treatment of acute lung injury (Fig. 4). Below, the drug mechanisms are discussed and the results of clinical trials are combined to explain and analyze the therapeutic efficacy of these drugs and areas for improvement. The relevant pharmacological data of several current popular drugs are summarized in Table I.

Therapeutic drugs targeting the spike-ACE2 interaction. Certain currently available therapeutic drugs targeting ACE2 are discussed below.

i) Arbidol: Arbidol is a recommended anti-influenza drug. As a hemagglutinin inhibitor, the mechanism of action for COVID-19 is primarily through the activation of 2,5-oligoadenylate synthase in the human body, which is an antiviral protein that specifically inhibits the interaction between the S protein on the viral lipid envelope and ACE2 on the host cell membrane by interrupting adhesion and other interactions, blocking the process of viral gene penetration into the nucleus (DAA) (24). At the same time, arbidol can also act as a host targeting agent (HTA) by affecting the life cycle of the 
Table I. Pharmacological data of several current popular drugs for ACE2-centered therapy $(69,70,73,75,78,84,85)$.

\begin{tabular}{|c|c|c|c|}
\hline Name & Arbidol (ARB) & Chloroquine phosphate (CQ) & $\begin{array}{l}\text { Clinical-grade soluble human } \\
\text { ACE2 (hrsACE2) }\end{array}$ \\
\hline Mechanism & $\begin{array}{l}\text { Spike-ACE } 2 \text { and Affect the } \\
\text { virus life cycle }\end{array}$ & $\begin{array}{l}\text { Inhibit the process of virus } \\
\text { replication and block terminal } \\
\text { glycosylation modification of ACE2 }\end{array}$ & $\begin{array}{l}\text { Inhibit lung damage and prevent } \\
\text { virus invasion }\end{array}$ \\
\hline Pharmacokinetic and & $\mathrm{EC}_{50}=10 \mu \mathrm{M}$ & $\mathrm{EC}_{50}=1.13 \mu \mathrm{M}$ & Not reported (currently undergoing \\
\hline toxicological data & $\mathrm{CC}_{50}=20-100 \mu \mathrm{M}$ & $\mathrm{CC}_{50}=100 \mu \mathrm{M}$ & $\begin{array}{l}\text { Phase } 1 \text { and } 2 \text { clinical trials; } \\
\text { NCT00886353, NCT01597635) }\end{array}$ \\
\hline Applicable stage & Early stage of viral infection & Pneumonia worsening stage & $\begin{array}{l}\text { Prevent infection stage; } \\
\text { late lung injury stage }\end{array}$ \\
\hline Suggested dose & $\begin{array}{l}200 \mathrm{mg} / \text { day }<10 \text { days for } \\
\text { adults }\end{array}$ & $1,000 \mathrm{mg} /$ day (twice) for 7 days & $25-200 \mu \mathrm{g} /$ day \\
\hline $\begin{array}{l}\text { Combination } \\
\text { medication }\end{array}$ & $\begin{array}{l}\text { With IFN- } \alpha \text { or other } \\
\text { antiviral drug }\end{array}$ & $\begin{array}{l}\text { High CQ doses are not } \\
\text { recommended when with } \\
\text { azithromycin or oseltamivir }\end{array}$ & Not reported \\
\hline $\begin{array}{l}\text { Possible adverse } \\
\text { reactions }\end{array}$ & Not reported & $\begin{array}{l}\text { May increase the risk of fatal } \\
\text { ventricular arrhythmia }\end{array}$ & $\begin{array}{l}\text { May increase the risk of virus } \\
\text { infection }\end{array}$ \\
\hline $\begin{array}{l}\text { Problems to be } \\
\text { solved }\end{array}$ & $\begin{array}{l}\text { Standardized animal studies } \\
\text { and controlled clinical trials }\end{array}$ & $\begin{array}{l}\text { The gap between in vitro antiviral } \\
\text { activity and clinicaleffect; } \\
\text { standardized diagnosis and } \\
\text { treatment plan yet to be formulated }\end{array}$ & $\begin{array}{l}\text { The impact of hrsACE } 2 \text { in the later } \\
\text { stages of the disease process }\end{array}$ \\
\hline
\end{tabular}

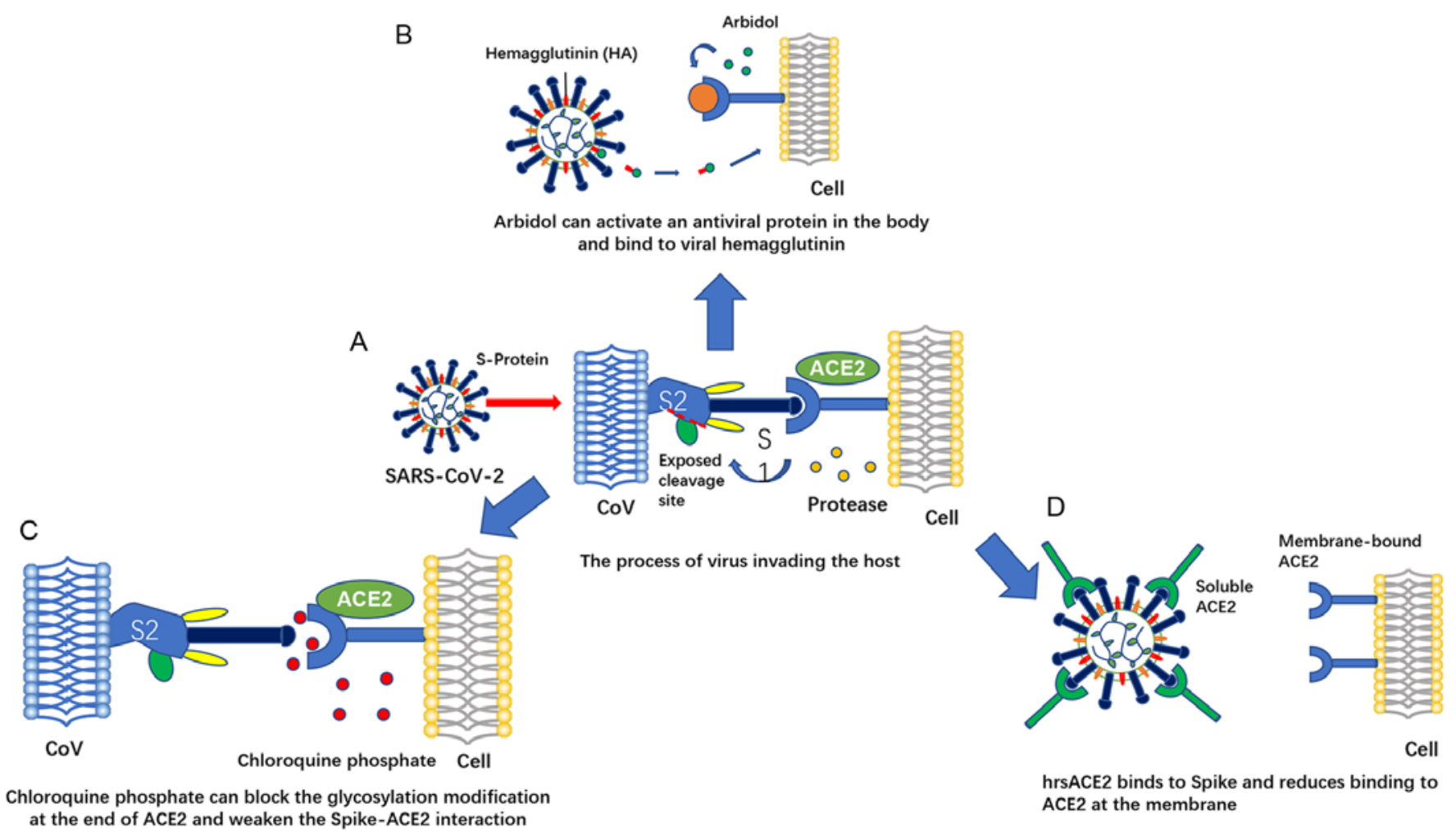

Figure 4. Process of the virus invading the host and the mechanism of action of several key drugs. (A) SARS-CoV2 recognizes and binds to ACE2 of the host cell to enter the cell. (B) As a hemagglutinin inhibitor, arbidol can directly bind to the viral hemagglutinin to block its invasion of the host, and it can also activate an antiviral protein (2,5-oligoadenylate synthase) in the body to prevent Interaction between S protein and host ACE2. (C) Chloroquine phosphate can reduce the interaction of Spike-ACE2 by blocking the glycosylation modification at the end of ACE2, thereby inhibiting virus invasion. (D) Recombinant human soluble ACE2 (hrsACE2) can bind to the virus S protein and compete with the host ACE2 for binding sites to inhibit virus invasion.

virus. Results from preclinical animal toxicology experiments have demonstrated that arbidol has good toxicological safety.
The lethal dose demonstrated in experiments using mice has been shown to be approximately 40 -fold the dose used in 
humans (68); clinical use records have reported arbidol to be extremely well tolerated and to have a high therapeutic index. In a retrospective study, the total effective rate of arbidol antiviral therapy was $75 \%$ (69), and no severe adverse reactions were observed (70), with its resistance primarily arising from mutations in the HA2 fusion protein. Although the drug has been used as an antiviral drug for influenza for a number of years, it has not yet produced significant viral resistance. The main part of arbidol metabolism occurs in the liver, but rapidly spreads to various tissues. Within $48 \mathrm{~h}$, approximately $40 \%$ of arbidol intake is excreted in feces.

Through searching past antiviral randomized controlled studies of arbidol and clinical studies in which it was used in patients with COVID-19, arbidol appears to have a positive antiviral effect. On February 4, 2020, the research team of Lanjuan announced that in vitro cell experiments revealed that very low concentrations of arbidol effectively inhibited SARS-CoV-2 by 60 -fold compared with the control group without drug treatment, significantly inhibiting the pathological effect of the virus on the cells. However, the team has not yet published the study, and thus this is not conclusive evidence. At present, arbidol has been used as an antiviral drug in COVID-19 patients and applied during the early stages of viral infection. Previous studies have also demonstrated that, including various coronaviruses and influenza viruses, arbidol exhibits broad-spectrum antiviral activity $(71,72)$. In the 'New Coronavirus Infection Pneumonia Diagnosis and Treatment Plan (Trial Version 6)', arbidol was recommended for the first time for the antiviral treatment of patients with COVID-19 (http://www.nhc.gov.cn/yzygj/s7653p/202002/83 34a8326dd94d329df351d7da8aefc2.shtml). According to the guidelines, the use of interferon (IFN)- $\alpha$ is recommended in combination with arbidol or other antiviral drugs for $<10$ days as an anti-COVID-19 therapy; however, there are currently no large-scale clinical studies available on arbidol/IFN- $\alpha$ in COVID-19 information or research. In a recent study, arbidol combined with IFN- $\alpha 2 b$ was no more effective than IFN- $\alpha 2 b$ as a single agent in COVID-19 with respect to RNA clearance and hospitalization, raising questions as to the use of arbidol (73).

Based on a large amount of literature, arbidol has great potential for use in the treatment of patients with COVID-19; however, at present, the efficacy and toxicity of the drug for COVID-19 remains uncertain, and the combination of IFN- $\alpha$ and arbidol used to obtain novel drug categories to improve efficacy should be further confirmed in larger prospective randomized studies. The relative lack of standardized animal studies and controlled clinical trials for healthy and infected subjects is also an issue that needs to be resolved. In view of the fact that patients with COVID-19 are administered several drugs and their clinical course is complex, it is necessary to perform pharmaceutical monitoring following the administration of these drugs to patients. Moreover, both in vivo and in vitro studies have demonstrated that arbidol can be used in combination with other antiviral drugs for the treatment of patients with COVID-19 to obtain improved therapeutic effects; however, the antiviral effects and mechanisms of action of arbidol alone require more in-depth investigation in further clinical studies.

ii) Chloroquine phosphate $(C Q)$ : As a basic compound, chloroquine reduces the interaction of spike-ACE2 by blocking the glycosylation modification at the end of ACE2, inhibiting the virus from invading Vero E6 cells (74). Chloroquine also increases the $\mathrm{pH}$ of vesicles and blocks the replication process of $\mathrm{pH}$-dependent viruses, such as coronaviruses. Due to the lack of reliable information on the target concentration or dose in COVID-19, the 'loading dose' for adults $(30 \mathrm{mg} / \mathrm{kg}$ within $48 \mathrm{~h}$ ) and children (70 mg/kg within 5 days) is currently used as a clinical reference. Early toxicological test results have suggested that the safety of the drug needs to be investigated. For mice, the injection of CQ at $60 \mathrm{mg} / \mathrm{kg}$ per day for 4 consecutive weeks leads to a $30-40 \%$ fatality rate. It has not yet been determined whether the use of much lower doses that are currently recommended will ensure the safety of this combination of drugs, and prescribers should exercise caution. However, it was clinically observed that the high-dose group (600 mg CQ) compared with the low-dose group (300 mg CQ) experienced a reduced fatality rate of at least $50 \%$ (75).

CQ has been used in the treatment of malaria and autoimmune diseases for $>70$ years, and it has also been proven to have positive effects against a variety of coronaviruses (76). Chloroquine compounds were first demonstrated in in vitro tests at the end of 2019 to effectively inhibit the invasion of SARS-CoV-2 and were subsequently considered to be effective in attenuating the progression of pneumonia and lung damage. As a result of imaging, the viral load is reduced, and therefore, the course of the disease is shortened, increasing the survival rate (77). The National Health Commission released the 'New Coronavirus Pneumonia Diagnosis and Treatment Plan (Trial Sixth Edition)' on February 18, 2020, adding CQ as an antiviral trial drug (http://www.nhc.gov.cn/yzygj/s7653p/ 202002/8334a8326dd94d329df351d7da8aefc2.shtml). An in vitro antiviral study at the Wuhan Institute of Virology has demonstrated that the median effective concentration $\left(\mathrm{EC}_{50}\right)$ of chloroquine is $1.13 \mu \mathrm{mol} / \mathrm{l}(0.36 \mathrm{mg} / \mathrm{l})$, and it exerts antiviral effects during and after the viral entry stage (77). At present, there are $>30$ clinical studies of CQ in the treatment of COVID-19 at home and abroad. According to published briefings, clinical treatment observations from $>100$ patients have indicated that CQ inhibits the deterioration of pneumonia, improves lung imaging results and inhibits viruses. In terms of decreasing the disease course, $\mathrm{CQ}$ is superior to the control treatment, and there were no severe adverse reactions to CQ in the above-mentioned patients (78).

Although CQ has been tested clinically and has acceptable safety, there are also some potential safety issues and prolonged use risks, including a prolonged QT interval, ventricular tachycardia and retinopathy, etc., which may increase the risk of fatal ventricular arrhythmia (79). Therefore, safety is a key concern in the current application of chloroquine. According to previous findings, the therapeutic dose of chloroquine is very close to the toxic and lethal doses, and the plasma drug concentration at a dose of $500 \mathrm{mg} /$ day will exceed EC90 $(6.90 \mu \mathrm{mol} / \mathrm{l})(80)$. Therefore, overdosing should be avoided in clinical practice. Previous research has indicated that the ACE2 receptor used by ARS-CoV-2 to enter cells is highly expressed in cells, such as the lungs, gastrointestinal tract, kidneys and heart, facilitating SARS-coronavirus 2 entry into these organs (81). According to previous research, CQ highly and slowly accumulates in these organs (79). Therefore, the distribution of CQ in these organs may be highly associated 
with its potential efficacy against SARS-CoV-2 and adverse events. However, according to the currently recommended dosing regimen for the treatment of malaria or rheumatoid arthritis, the concentration of the drug at the site of action may be much higher than the effective concentration $\left(\mathrm{EC}_{50}\right)$ required to inhibit SARS-CoV-2 in vitro, and a higher accumulation of tissue CQ may lead to adverse events. At the same time, due to the potential safety hazards of COVID-19 in critically ill patients, particularly when taking azithromycin and oseltamivir at the same time, higher CQ doses have proven to be dangerous.

Therefore, objectively speaking, although the drug achieves good efficacy in the treatment of COVID-19 patients, its safety may be a major obstacle to its application in the future. Among infected patients, approximately $30 \%$ are elderly and approximately $2 \%$ are pregnant women and children, and the probability of complications in these populations is higher (21). At the same time, in obese patients, if total body weight is used instead of calculating the dose by ideal weight, obese patients may be administered an overdose, as these drugs are not retained in adipose tissue. Therefore, there is an urgent need for the development of a personalized drug delivery strategy for each vulnerable group to safely and effectively use CQ against SARS-CoV-2. Recent research has found that the in vitro antiviral activity of CQ does not necessarily translate into clinical efficacy in vivo (82). In view of the fact that the mechanisms of drug metabolism in the body remain unclear, this is also an urgent issue to be solved. Therefore, considering the exposure-efficacy and exposure-safety association of CQ to optimize its dosage in each special population is a direction for future development, and when medical conditions permit, it is recommended that in the treatment of novel coronary pneumonia, whole blood concentration of the drug after taking CQ should be closely monitored to adjust the dosage of CQ according to the blood concentration to formulate a more precise individualized treatment plan. An electrocardiogram (ECG) should be closely monitored as well to prevent adverse reactions.

Targeted regulation of ACE2 content and treatment methods. The content of ACE2 as regards various treatment methods is discussed below.

i) Clinical-grade soluble human ACE2: A previous study demonstrated that human recombinant soluble ACE2 (hrsACE2) reduced the recovery ability of SARS-CoV-2 in Vero cells by 1000-5,000-fold. There have since been phase 1 and 2 clinical trials conducted, both of which have proven that in the early stage of infection, hrsACE2 significantly inhibits the infection of human organs and organoids, hindering the growth of the virus $(83,84)$. Its coefficient for Vero E6 cells is 1,000-5,000. Moreover, SARSCoV-2 directly infects engineered human vascular organs and renal organs, and hrsACE2 inhibits its infection (85). Recombinant ACE2 may also effectively be used for the treatment of acute lung failure in mice and eliminates the lung injury effect caused by SARS protein by regulating the ACE2 pathway (81). In other lung injury models, such as bleomycin-induced pulmonary fibrosis and monocrotaline-induced pulmonary hypertension, recombinant ACE2 has recently been shown to prevent chronic lung injury, fibrosis, and pulmonary vasoconstriction (85). These results suggest that recombinant ACE2 can be used clinically as a novel treatment for chronic organ failure and acute lung injury.

However, it must also be considered that compared with endosomal ACE, endogenous circulating levels of soluble ACE2 are usually very low or even undetectable, and SARS-CoV-2 cannot be sufficiently isolated in the circulation to prevent spread of the virus. The degree to which artificial recombinant ACE2 competes with SARS-CoV-2 to reduce viremia infection and tissue damage is still unclear. At present, only the effect of hrsACE2 on early infection by the virus is understood; however, the effect of hrsACE2 in later stages of the disease process is not clear, and its effects on the lungs are also poorly understood (86). A clinical trial on the infusion of ACE2 protein in the stress group was also withdrawn. Although increasing ACE2 protein content to increase the ratio of Ang-(1-7): AngII may have a certain improvement effect on organ damage induced by SARS-CoV-2, this method may also be beneficial for viral invasion through the respiratory or digestive system. When patients experience ARDS, it may alleviate subsequent viral infections in other tissues; however, ACE2 infusion may reduce circulating AngII levels and increase Ang(1-7) levels to promote infectious or cardiogenic effects in later stages of the disease, including shock. Patients with COVID-19 may experience blood pressure imbalance, leading to hypotension.

In brief, it can be concluded that the research and development of artificial hrsACE2 is still in a relatively immature stage, and the relevant research results are still inconclusive. In view of the complex effects of ACE2 levels on viral infections, every step of the research in the future must be taken cautiously.

ii) RAS inhibition: ACE2 is a component of RAS and participates in the occurrence and development of hypertension together with ACE. RAS inhibitors are drugs that need to be chronically taken by hypertensive patients. Although it seems that there are different responses to ARBs and ACEIs, as well as tissue-related responses, the notion that RAAS block stimulates ACE2 expression and activity has typically been supported by experimental studies (87-89). Recently, it was discovered that in the hearts of mice with aortic stenosis, various ARBs (olmesartan, losartan, valsartan, candesartan, telmisartan and irbesartan) are all present to a similar degree ( $\sim 2$ times) and increase ACE2 protein levels $(90,91)$. Among patients with chronic kidney disease (CKD), urinary ACE2 levels (tubular expression index) in patients treated with ACEIs or ARBs are similar to those in untreated patients. In addition, Kocks et al found that ACEI treatment had no effect on the expression of ACE2 protein in kidney biopsy samples of patients with various kidney diseases and kidney transplant recipients (92). By contrast, only patients treated with ACEI had higher intestinal ACE2 mRNA levels than ARB (93). However, ACE2 protein or activity was not evaluated to verify the mRNA results. In addition to RAAS inhibitors, experimental studies have indicated that statins enhance the expression of ACE2. Tikoo et al reported increased ACE2 protein levels in the heart and kidney of atherosclerotic rabbits treated with atorvastatin (approximately 2-fold), which was related to epigenetic modification of the ACE2 gene (94). Fluvastatin treatment has been shown to significantly enhance the effect of insulin on inducing the expression of ACE2 
protein in the heart of diabetic rats (95). As far as is known, the effect of ARB or ACEI therapy combined with statins on ACE2 expression has not yet been determined. Finally, peroxisome proliferator-activated receptor- $\gamma$ (PPAR- $\gamma$ ) may also affect expression of ACE2. After the aorta is narrowed, the PPAR- $\gamma$ agonist rosiglitazone causes the aorta of hypertensive rats to increase ACE2 content (96). Researchers in Austrian found that in acute lung injury caused by SARS and certain influenza viruses, ACE2 buffers pulmonary fibrosis and lung injury caused by excessive activation of RAS to a certain extent (97). Studies using experimental animal lung injury models have demonstrated that RAS-induced upregulation of ACE2 by inhibitors can reduce lung injury (98). Various ACE inhibitors, such as captopril and lisinopril, do not affect the activity of ACE2, and ACE2 activity can be inhibited by the dipeptide Pro-Phe. Specific ACE2 inhibitors have been developed accordingly, such as the peptide analog DX600 and MLN 4760 \{(S,S)-2-[1-carboxy-2-[3-(3,5-dichlorobenzyl)$3 \mathrm{H}$-imidazol4-yl]-ethylamino]-4-methyl Valeric acid\}. MLN 4760 is the first rationally designed ACE2 inhibitor based on the carbon-terminal dipeptide of AngI (His-Leu) with high potency $(\mathrm{Ki}=0.44 \mathrm{nM})$ and specificity (99).

The current understanding of the cardiovascular consequences in patients with SARS-CoV-2 infection at this early stage is very limited. Lo et al reported that circulating levels of AngII in patients with COVID-19 were significantly higher than those in healthy controls, which is consistent with the lower activity of ACE2. However, compared with experimental data, particularly regarding the impact of ACEI and ARB, the current ACE2-Ang(1-7) clinical data on the pathway is very limited (99). In addition, although the existing evidence is novel and insightful, it usually comes from smaller cross-sectional observational studies. Therefore, RAAS measurement is incomplete and cannot fully explain the potential bias and confusion.

In summary, it is still controversial whether RAS inhibitors are a 'nemesis' or 'accomplice' of COVID-19, and there is no definite clinical evidence on whether RAS inhibitors aggravate the condition of COVID-19 (100). The test results of different RAS inhibitors affecting ACE2 expression and enzyme activity are inconsistent, and related research is still advancing. In view of the fact that the biological effects of basic research are not equivalent to clinical effects, RAS inhibitors should not be rashly activated or stopped in response to ambiguous research results.

New insight based on the SARS-CoV epidemic experience. Research indicated that serum from SARS patients during the recovery period prevents the invasion of SARS-CoV-2, revealing the important commonality between SARS-CoV-2 and SARS-CoV infection (89). Therefore, when there are no specific drugs available for the treatment of COVID-19, it is a fruitful practice to refer to the epidemic experience in 2003 for the new use of old drugs. This is discussed below.

i) Griffithsin (GRFT): GRFT is a lectin extracted from red algae. This lectin has a domain-swapped dimeric structure in which $2 \beta$-strands of one monomer combine with $10 \beta$-strands of the other monomer to form a $\beta$-prism of 34 -stranded sheets (101). Each GRFT monomer (mGRFT) contains 3 binding sites with high affinity for mannose residues, and this compound is one of the most potent microbicides isolated to date. Mori et al confirmed the antiviral activity of GRFT in in vivo and in vitro experiments in SARS-CoV studies (102). In vitro, GRFT specifically binds to the recombinant SARS-CoV S protein in a dose-dependent manner, although it cannot significantly inhibit the subsequent binding of ACE2 to the spike protein. Interestingly, Mori et al found that GRFT significantly ameliorated pulmonary edema lesions and alleviated necrotizing bronchiolitis in mice following SARS-CoV infection, as well as significantly downregulating the production of pro-inflammatory cytokines, such as cytokines IL-1 $\alpha$, IL-1 $\beta$, IL-6, G-CSF, MCP-1 and IL-12 in lung tissue (102). This reminds us that the subsequent development of GRFT is likely to be performed in the setting of cytokine storms.

ii) Antibodies or peptide drugs that strongly block spike-ACE2 binding: Passive immunization may be an effective treatment for COVID-19, which requires the use of agents that can neutralize the virus, either sera from persons recovering from SARS-CoV-2 infection or purified antibodies, in patients.

In a study on SARS-CoV, Hu et al found that a peptide fragment $S$ of viral RBD specifically blocked the binding of spike RBD-ACE2 and inhibited infection in in vitro experiments (103). Han et al used an alanine scanning mutagenesis method and found that the peptide composed of 2 ACE2 modules linked by glycine exhibited potent antiviral activity $\left(\mathrm{IC}_{50}=0.1 \mu \mathrm{mol} / \mathrm{l}\right)(104)$. Therefore, an effective method to block the RBD-ACE2 interaction of the Newcomb virus is to search for RBD domain-based peptides or their combination cocktails. However, it must be noted that although antibodies to SARS-CoV have been shown to achieve good efficacy, SARS-CoV2 and SARS-CoV spike RBD amino acid sequence identity is only $72 \%$; thus, therapeutic antibodies and peptides targeting SARS-CoV RBD interact weakly with the new coronary virus RBD, and many do not even cross-react with SARS-CoV-2. Therefore, some degree of modification of existing drugs is necessary to obtain better efficacy.

Recently, investigators from Vanderbilt University Medical Center and other institutions have discovered a number of monoclonal antibodies (mAbs) with effective neutralizing activity that completely block the interaction between $S$ protein receptor-binding region (SRBD) and human ACE2 receptor (hACE2) from a large number of human mAbs against spike glycoproteins. Researchers found that these neutralizing monoclonal antibodies effectively recognized nonoverlapping sites while binding to the $\mathrm{S}$ protein and synergistically neutralized the authentic SARS-CoV-2 virus. At the same time, it was also demonstrated in 2 mouse SARS-CoV-2 infection models that passive infusion of COV2-2196, COV2-2130, or the combination of these $2 \mathrm{mAbs}$ protected mice from weight loss and reduced viral burden and lung inflammation. In addition, researchers found that passive infusion of the 2 most potent ACE2-blocking monoclonal antibodies (COV2-2196 or COV2-2381) as a single treatment protected rhesus monkeys from SARS-CoV-2 infection. Collectively, these results identify protective epitopes for SRBD and provide a structure-based framework for rational vaccine design and selection of potent immunotherapies (105).

Coincidentally, Huo et al reported 2 closely related nanobodies (H11-H4 and H11-D4) that could block SARS-CoV-2 
spike binding to ACE2 in cell culture (106). One protein region targeted by these nanobodies is closely adjacent to the ACE2 binding region and has a small amount of overlap. Both nanobodies exhibited the ability to neutralize live SARS-CoV-2, with H11-H4 being particularly potent and enhanced in combination with human-derived antibodies. The authors suggested that these nanobodies could be used alone or in combination with other antibodies to help achieve passive immunization in critically ill patients with COVID-19. Since camelid animal-derived antibodies are highly conserved with human-derived antibodies, they may only produce a low immune response in humans, but a well-developed humanization strategy can be exploited.

An important line of defense against SARS-CoV-2 is the formation of neutralizing antibodies that can eliminate invaders and have great potential in preventing and treating viral infections. Therefore, from the perspective of humoral immunity, the development of antibodies or peptides that can potently block the binding of SARS-CoV-2 spikes to ACE2 will be an important method for the prevention and treatment of COVID-19 at present.

Identification of other components of RAS as targets for intervention. Studies have demonstrated that ACE2 expression is positively associated with genes for viral entry, release and cellular immunity, but negatively associated with viral transcription, protein translation, humoral immunity, phagocytosis and complement activation. This suggests that ACE2 may play a dual role in mediating susceptibility and immunity to SARS-CoV-2 infection, making the idea of directly using ACE2 as a target for drug intervention a dilemma. Therefore, the identification of other intervention targets related to ACE2 may become a future research hotspot.

Considering that risk factors associated with hospitalization and mortality in patients with metabolic diseases, including obesity, arterial hypertension, cardiovascular disease and diabetes, may reflect global activation of the RAS system, modulation of RAS homeostasis through the ACE2/(Ang1-7)/MAS pathway should be considered to improve patient symptoms. The Mas gene is an intrinsic receptor for Ang1-7 and is highly conserved. Ang1-7 plays an important regulatory role in neuroplasticity, memory and anxiety by acting on Mas receptors to exert anti-angiogenic, vasodilatory, anti-proliferative, anti-fibrotic and antithrombotic effects.

In addition, clinical observational studies have found that in the majority of cases, respiratory distress occurs following a period of infection (usually approximately 14 days), suggesting that this phenomenon may not be a direct effect of the initial viral infection, but rather a host response to loss of ACE2 function, dysregulation of the AngII/ACE2 pathway, and activation of autoproteases. The current central hypothesis is that the binding of viral spike proteins to ACE2 leads to the shedding of ACE2 receptors by various proteases, which in turn leads to the loss of protective function of the ACE2/MAS axis in the lung and other organs. In addition to the loss of this protective function, tissue-specific proteases (e.g., cathepsins, chymotrypsin-like) activate the classical pathway (ACE/RAS/AngII) and the alternative pathway, also leading to AngII overproduction at the tissue level. This process may further change the balance of Ang1-7/MAS and ACE2 protective function, thereby alleviating the adverse effects of AngII elevation on pulmonary epithelial and intravascular injury.

Thus, the induction of ACE2 downstream pathways through the activation of the ACE2/ang1-7/MAS axis may be an effective strategy to prevent pulmonary and cardiovascular injury due to SARS-CoV-2 infection. Due to decreased ACE2/MAS activity and enhanced AngII/AT1R activity, the risk of pulmonary vascular endothelial/epithelial cell injury and lung histopathology is increased. The inhibition of protease activity, the necessary cleavage of viral spike proteins to prevent virus interaction with receptors and their entry into cells, such as ADAM17 and transmembrane serine protease 2 (TMPRSS2), which inhibit enzyme activity, may be exploited as a novel therapeutic target. In addition, it is feasible to use the protective effects of Ang1-7 or its analogs, such as AVE0991 (107), to counteract the deleterious effects of increased AngII and may be effective in the symptomatic treatment of these patients.

\section{Conclusions and future perspectives: Potentials and pitfalls}

The present review began by discussing the physiological function of ACE2 and summarizing the impact of ACE2 content on viral susceptibility and acute lung injury. Subsequently, from the perspective of drug mechanisms, combined with the results of clinical trials, several ACE2-centric treatments are specifically elaborated and analyzed. The drug efficacy and areas that need improvement are also reviewed. The research presented herein, to a certain extent, may assist medical workers to correctly understand the role of ACE2 in the disease process, understand the complex effects of the substance in viral infections and acute lung injury, and use ACE2 centered drug therapy in a prudent and standard manner. At the same time, several therapies and mechanisms related to ACE2 listed in the present review article can also provide researchers with certain ideas for developing new drugs.

The effects of ACE2 on sensitivity to the novel coronaviruses and acute lung injury must be investigated. The data presented herein suggest that when the ACE2 content is too high, it can attenuate the rate of viral invasion and reduce the degree of destruction in acute lung injury; however, it also enhances viral replication capacity and sensitivity. When the ACE2 content is low, it hinders the replication ability of the virus, but at the same time, it leads to increased AngII levels, plays a role in promoting inflammation and fibrosis, and induces multiple organ damage. Despite the limitations and risks of existing diagnostic and therapeutic regimens for ACE2 and the fact that most drugs have not yet undergone large-scale clinical trials, we still cannot ignore the therapeutic potential of ACE2 as a key receptor for viral invasion.

As regards future directions, a strict evaluation of existing drugs and regimens needs to be conducted, to standardize the use of doses, rationally combine drugs, and establish a sound regulatory mechanism. Lessons can also be learnt from the experience of SARS-CoV with respect to anti-pandemic and innovative research ideas and begin to explore the directions of 'other components of RAS as intervention targets' and 'clinical-grade soluble human ACE2'. In this manner, the therapeutic potential of ACE2 as a key receptor for viral invasion can be fully taken advantage of to obtain the best therapeutic effect. 
However, the present review article also has certain limitations. For example, a number of the studies cited in the article are still in progress, and no definite and comprehensive conclusions have been drawn yet. The present review only focused on the existing results. Moreover, there are numerous ACE2-centered drug therapies, and only the 4 most common therapies were discussed herein. Finally, large-scale clinical retrospective studies on patients with COVID-19 have not yet been performed, at least to the best of our knowledge. Thus, the conclusions drawn may not be accurate or universal enough.

\section{Acknowledgements}

Not applicable.

\section{Funding}

No funding was received.

\section{Availability of data and materials}

Not applicable.

\section{Authors' contributions}

GY and MF conceived the study subject, and critically reviewed the intellectual content of the manuscript and made substantive revisions to the important contents of the manuscript. LC and $\mathrm{XG}$ were the major contributors to the writing of the manuscript, and assisted in the literature search. YC, YZ, PY and LH provided suggestions and technical support and revised important sections of the manuscript, and assisted in the literature search. All authors read and approved the final manuscript.

\section{Ethics approval and consent to participate}

Not applicable.

\section{Patient consent for publication}

Not applicable.

\section{Competing interests}

The authors declare that they have no competing interests.

\section{References}

1. Lu R, Zhao X, Li J, Niu P, Yang B, Wu H, Wang W, Song H, Huang B, Zhu N, et al: Genomic characterisation and epidemiology of 2019 novel coronavirus: Implications for virus origins and receptor binding. Lancet 395: 565-574, 2020.

2. Guan WJ, Ni ZY, Hu Y, Liang WH, Ou CQ, He JX, Liu L, Shan H, Lei CL, Hui DSC, et al: Clinical characteristics of coronavirus disease 2019 in China. N Engl J Med 382: 1708-1720, 2020.

3. Yang X, Yu Y, Xu J, Shu H, Xia J, Liu H, Wu Y, Zhang L, Yu Z, Fang M, et al: Clinical course and outcomes of critically ill patients with SARS-CoV-2 pneumonia in Wuhan, China: A single-centered, retrospective, observational study. Lancet Respir Med 8: 475-481, 2020.

4. Gralinski LE and Menachery VD: Return of the Coronavirus: 2019-nCoV. Viruses 12: 135, 2020.

5. Wang G and Jin X: The progress of 2019 novel coronavirus event in China. J Med Virol 92: 468-472, 2020.
6. Fouchier RA, Hartwig NG, Bestebroer TM, Niemeyer B, de Jong JC, Simon JH and Osterhaus AD: A previously undescribed coronavirus associated with respiratory disease in humans. Proc Natl Acad Sci USA 101: 6212-6216, 2004

7. Guo YR, Cao QD, Hong ZS, Tan YY, Chen SD, Jin HJ, Tan KS Wang DY and Yan Y: The origin, transmission and clinical therapies on coronavirus disease 2019 (COVID-19) outbreak-an update on the status. Mil Med Res 7: 11, 2020.

8. Patel S, Rauf A, Khan H and Abu-Izneid T: Renin-angiotensinaldosterone (RAAS): The ubiquitous system for homeostasis and pathologies. Biomed Pharmacother 94: 317-325, 2017.

9. Kuba K, Imai Y, Ohto-Nakanishi T and Penninger JM: Trilogy of ACE2: A peptidase in the renin-angiotensin system, a SARS receptor, and a partner for amino acid transporters. Pharmacol Ther 128: 119-128, 2010.

10. Hamming I, Cooper ME, Haagmans BL, Hooper NM, Korstanje R, Osterhaus AD, Timens W, Turner AJ, Navis G and van Goor $\mathrm{H}$ : The emerging role of ACE2 in physiology and disease. J Pathol 212: 1-11, 2007.

11. Kuhn JH, Li W, Choe H and Farzan M: Angiotensin-converting enzyme 2: A functional receptor for SARS coronavirus. Cell Mol Life Sci 61: 2738-2743, 2004.

12. Xu X, Chen P, Wang J, Feng J, Zhou H, Li X, Zhong W and Hao P: Evolution of the novel coronavirus from the ongoing Wuhan outbreak and modeling of its spike protein for risk of human transmission. Sci China Life Sci 63: 457-460, 2020.

13. Wrapp D, Wang N, Corbett KS, Goldsmith JA, Hsieh CL, Abiona O, Graham BS and McLellan JS: Cryo-EM structure of the 2019-nCoV spike in the prefusion conformation. Science 367: 1260-1263, 2020.

14. Tipnis SR, Hooper NM, Hyde R, Karran E, Christie G and Turner AJ: A human homolog of angiotensin-converting enzyme. Cloning and functional expression as a captopril-insensitive carboxypeptidase. J Biol Chem 275: 33238-33243, 2000.

15. Donoghue M, Hsieh F, Baronas E, Godbout K, Gosselin M Stagliano N, Donovan M, Woolf B, Robison K, Jeyaseelan R, et al: A novel angiotensin-converting enzyme-related carboxypeptidase (ACE2) converts angiotensin I to angiotensin 1-9. Circ Res 87: E1-E9, 2000.

16. Rice GI, Thomas DA, Grant PJ, Turner AJ and Hooper NM: Evaluation of angiotensin-converting enzyme (ACE), its homologue ACE2 and neprilysin in angiotensin peptide metabolism. Biochem J 383: 45-51, 2004.

17. Soubrier F, Alhenc-Gelas F, Hubert C, Allegrini J, John M, Tregear $\mathrm{G}$ and Corvol $\mathrm{P}$ : Two putative active centers in human angiotensin I-converting enzyme revealed by molecular cloning. Proc Natl Acad Sci USA 85: 9386-9390, 1988.

18. Ehlers MR and Riordan JF: Angiotensin-converting enzyme: Zinc- and inhibitor-binding stoichiometries of the somatic and testis isozymes. Biochemistry 30: 7118-7126, 1991.

19. Patel VB, Zhong JC, Grant MB and Oudit GY: Role of the ACE2/Angiotensin 1-7 axis of the renin-angiotensin system in heart failure. Circ Res 118: 1313-1326, 2016.

20. Te Riet L, van Esch JH, Roks AJ, van den Meiracker AH and Danser AH: Hypertension: Renin-angiotensin-aldosterone system alterations. Circ Res 116: 960-975, 2015.

21. Baig AM, Khaleeq A, Ali U and Syeda H: Evidence of the COVID-19 virus targeting the CNS: Tissue distribution, host-virus interaction, and proposed neurotropic mechanisms. ACS Chem Neurosci 11: 995-998, 2020.

22. Li JW, Han TW, Woodward M, Anderson CS, Zhou H, Chen YD and Neal B: The impact of 2019 novel coronavirus on heart injury: A systematic review and meta-analysis. Prog Cardiovasc Dis 63: $518-524,2020$.

23. Hamming I, Timens W, Bulthuis ML, Lely AT, Navis G and van Goor H: Tissue distribution of ACE2 protein, the functional receptor for SARS coronavirus. A first step in understanding SARS pathogenesis. J Pathol 203: 631-637, 2004.

24. Hoffmann M, Kleine-Weber H, Schroeder S, Krüger N, Herrler T, Erichsen S, Schiergens TS, Herrler G, Wu NH, Nitsche A, et al: SARS-CoV-2 cell entry depends on ACE2 and TMPRSS2 and is blocked by a clinically proven protease inhibitor. Cell 181: 271-280.e8, 2020.

25. Yan R, Zhang Y, Li Y, Xia L, Guo Y and Zhou Q: Structural basis for the recognition of SARS-CoV-2 by full-length human ACE2. Science 367: 1444-1448, 2020.

26. Kuba K, Imai Y, Rao S, Gao H, Guo F, Guan B, Huan Y, Yang P, Zhang Y, Deng W, et al: A crucial role of angiotensin converting enzyme 2 (ACE2) in SARS coronavirus-induced lung injury. Nat Med 11: 875-879, 2005. 
27. Jiang F, Deng L, Zhang L, Cai Y, Cheung CW and Xia Z: Review of the clinical characteristics of coronavirus disease 2019 (COVID-19). J Gen Intern Med 35: 1545-1549, 2020.

28. Bourgonje AR, Abdulle AE, Timens W, Hillebrands JL, Navis GJ, Gordijn SJ, Bolling MC, Dijkstra G, Voors AA, Osterhaus AD, et al: Angiotensin-converting enzyme 2 (ACE2), SARS-CoV-2 and the pathophysiology of coronavirus disease 2019 (COVID-19). J Pathol 251: 228-248, 2020.

29. da Silva JS, Gabriel-Costa D, Wang H, Ahmad S, Sun X, Varagic J, Sudo RT, Ferrario CM, Dell Italia LJ, Sudo GZ and Groban L: Blunting of cardioprotective actions of estrogen in female rodent heart linked to altered expression of cardiac tissue chymase and ACE2. J Renin Angiotensin Aldosterone Syst 18 : $1470320317722270,2017$.

30. Zhou P, Yang XL, Wang XG, Hu B, Zhang L, Zhang W, Si HR, Zhu Y, Li B, Huang CL, et al: A pneumonia outbreak associated with a new coronavirus of probable bat origin. Nature 579: 270-273, 2020

31. Walls AC, Park YJ, Tortorici MA, Wall A, McGuire AT and Veesler D: Structure, function, and antigenicity of the SARS-CoV-2 Spike Glycoprotein. Cell 181: 281-292.e6, 2020.

32. Ye R and Liu Z: ACE2 exhibits protective effects against LPS-induced acute lung injury in mice by inhibiting the LPS-TLR4 pathway. Exp Mol Pathol 113: 104350, 2020

33. Oudit GY, Kassiri Z, Jiang C, Liu PP, Poutanen SM, Penninger JM and Butany J: SARS-coronavirus modulation of myocardial ACE2 expression and inflammation in patients with SARS Eur J Clin Invest 39: 618-625, 2009.

34. Chen N, Zhou M, Dong X, Qu J, Gong F, Han Y, Qiu Y, Wang J, Liu Y, Wei Y, et al: Epidemiological and clinical characteristics of 99 cases of 2019 novel coronavirus pneumonia in Wuhan, China: A descriptive study. Lancet 395: 507-513, 2020.

35. Inciardi RM, Lupi L, Zaccone G, Italia L, Raffo M, Tomasoni D, Cani DS, Cerini M, Farina D, Gavazzi E, et al: Cardiac involvement in a patient with coronavirus disease 2019 (COVID-19). JAMA Cardiol 5: 819-824, 2020

36. Burrell LM, Risvanis J, Kubota E, Dean RG, MacDonald PS Lu S, Tikellis C, Grant SL, Lew RA, Smith AI, et al: Myocardial infarction increases ACE2 expression in rat and humans. Eur Heart J 26: 369-375, 322-324, 2005.

37. Qi YF, Zhang J, Wang L, Shenoy V, Krause E, Oh SP, Pepine CJ, Katovich MJ and Raizada MK: Angiotensin-converting enzyme 2 inhibits high-mobility group box 1 and attenuates cardiac dysfunction post-myocardial ischemia. J Mol Med (Berl) 94: 37-49, 2016

38. Hashimoto T, Perlot T, Rehman A, Trichereau J, Ishiguro H, Paolino M, Sigl V, Hanada T, Hanada R, Lipinski S, et al: ACE2 links amino acid malnutrition to microbial ecology and intestinal inflammation. Nature 487: 477-481, 2012.

39. Ferrario CM and Mullick AE: Renin angiotensin aldosterone inhibition in the treatment of cardiovascular disease. Pharmacol Res 125: 57-71, 2017.

40. Meng J, Xiao G, Zhang J, He X, Ou M, Bi J, Yang R, Di W, Wang Z, Li Z, et al: Renin-angiotensin system inhibitors improve the clinical outcomes of COVID-19 patients with hypertension. Emerg Microbes Infect 9: 757-760, 2020.

41. Anker SD, Butler J, Khan MS, Abraham WT, Bauersachs J, Bocchi E, Bozkurt B, Braunwald E, Chopra VK, Cleland JG, et al: Conducting clinical trials in heart failure during (and after) the COVID-19 pandemic: An expert consensus position paper from the heart failure association (HFA) of the European society of cardiology (ESC). Eur Heart J 41: 2109-2117, 2020.

42. Zhu N, Zhang D, Wang W, Li X, Yang B, Song J, Zhao X, Huang B, Shi W, Lu R, et al: A novel coronavirus from patients with pneumonia in China, 2019. N Engl J Med 382: 727-733, 2020.

43. Huang C, Wang Y, Li X, Ren L, Zhao J, Hu Y, Zhang L, Fan G, $\mathrm{Xu}$ J, Gu X, et al: Clinical features of patients infected with 2019 novel coronavirus in Wuhan, China. Lancet 395: 497-506, 2020.

44. Kim S, Rigatto K, Gazzana MB, Knorst MM, Richards EM, Pepine CJ and Raizada MK: Altered gut microbiome profile in patients with pulmonary arterial hypertension. Hypertension 75 : 1063-1071, 2020

45. Santisteban MM, Kim S, Pepine CJ and Raizada MK Brain-gut-bone marrow axis: Implications for hypertension and related therapeutics. Circ Res 118: 1327-1336, 2016.

46. Cheng PK, Wong DA, Tong LK, Ip SM, Lo AC, Lau CS, Yeung EY and Lim WW: Viral shedding patterns of coronavirus in patients with probable severe acute respiratory syndrome. Lancet 363: 1699-1700, 2004.
47. Leung WK, To KF, Chan PK, Chan HL, Wu AK, Lee N, Yuen KY and Sung JJ: Enteric involvement of severe acute respiratory syndrome-associated coronavirus infection. Gastroenterology 125: 1011-1017, 2003.

48. Beli E, Yan Y, Moldovan L, Vieira CP, Gao R, Duan Y, Prasad R, Bhatwadekar A, White FA, Townsend SD, et al: Restructuring of the gut microbiome by intermittent fasting prevents retinopathy and prolongs survival in db/db mice. Diabetes 67: 1867-1879, 2018.

49. Vallianou NG, Stratigou T and Tsagarakis S: Microbiome and diabetes: Where are we now? Diabetes Res Clin Pract 146: $111-118,2018$

50. Budden KF, Gellatly SL, Wood DL, Cooper MA, Morrison M, Hugenholtz $\mathrm{P}$ and Hansbro PM: Emerging pathogenic links between microbiota and the gut-lung axis. Nat Rev Microbiol 15: 55-63, 2017.

51. Iyer SN, Lu D, Katovich MJ and Raizada MK: Chronic control of high blood pressure in the spontaneously hypertensive rat by delivery of angiotensin type 1 receptor antisense. Proc Natl Acad Sci USA 93: 9960-9965, 1996.

52. Sharma RK, Yang T, Oliveira AC, Lobaton GO, Aquino V, Kim S, Richards EM, Pepine CJ, Sumners C and Raizada MK: Microglial cells impact gut microbiota and gut pathology in angiotensin II-induced hypertension. Circ Res 124: 727-736, 2019.

53. Bron PA and Kleerebezem M: Lactic acid bacteria for delivery of endogenous or engineered therapeutic molecules. Front microbiol 9: 1821, 2018

54. Guzik TJ, Mohiddin SA, Dimarco A, Patel V, Savvatis K, Marelli-Berg FM, Madhur MS, Tomaszewski M, Maffia P, D'Acquisto F, et al: COVID-19 and the cardiovascular system: Implications for risk assessment, diagnosis, and treatment options. Cardiovasc Res 116: 1666-1687, 2020.

55. South AM, Diz DI and Chappell MC: COVID-19, ACE2, and the cardiovascular consequences. Am J Physiol Heart Circ Physiol 318: H1084-H1090, 2020.

56. Devaux CA, Rolain JM and Raoult D: ACE2 receptor polymorphism: Susceptibility to SARS-CoV-2, hypertension, multi-organ failure, and COVID-19 disease outcome. J Microbiol Immunol Infect 53: 425-435, 2020.

57. Li W, Moore MJ, Vasilieva N, Sui J, Wong SK, Berne MA, Somasundaran M, Sullivan JL, Luzuriaga K, Greenough TC, et al: Angiotensin-converting enzyme 2 is a functional receptor for the SARS coronavirus. Nature 426: 450-454, 2003.

58. Ge XY, Li JL, Yang XL, Chmura AA, Zhu G, Epstein JH, Mazet JK, $\mathrm{Hu} \mathrm{B}$, Zhang $\mathrm{W}$, Peng $\mathrm{C}$, et al: Isolation and characterization of a bat SARS-like coronavirus that uses the ACE2 receptor. Nature 503: 535-538, 2013.

59. Jia HP, Look DC, Shi L, Hickey M, Pewe L, Netland J, Farzan M, Wohlford-Lenane C, Perlman S and McCray PB Jr: ACE2 receptor expression and severe acute respiratory syndrome coronavirus infection depend on differentiation of human airway epithelia. J Virol 79: 14614-14621, 2005.

60. Wang J, Zhao S, Liu M, Zhao Z, Xu Y, Wang P, Lin M, Xu Y, Huang B, Zuo X, et al: ACE2 expression by colonic epithelial cells is associated with viral infection, immunity and energy metabolism. medRxiv: 2020-2022, 2020.

61. Cure E and Cumhur Cure M: Angiotensin-converting enzyme inhibitors and angiotensin receptor blockers may be harmful in patients with diabetes during COVID-19 pandemic. Diabetes Metab Syndr 14: 349-350, 2020.

62. Zeng Y, Zhang B, Zhang X and Yi C: Clinical characteristics of 9 cancer patients with SARS-CoV-2 infection. Chin Med 15: 47, 2020.

63. de Abajo FJ, Rodríguez-Martín S, Lerma V, Mejía-Abril G, Aguilar M,García-Luque A,LaredoL,LaosaO,Centeno-Soto GA, Ángeles Gálvez M, et al: Use of renin-angiotensin-aldosterone system inhibitors and risk of COVID-19 requiring admission to hospital: A case-population study. Lancet 395: 1705-1714, 2020.

64. Zhang P, Zhu L, Cai J, Lei F, Qin JJ, Xie J, Liu YM, Zhao YC, Huang $\mathrm{X}$, Lin L, et al: Association of inpatient use of angiotensin converting enzyme inhibitors and angiotensin II receptor blockers with mortality among patients with hypertension hospitalized with COVID-19. Circ Res 126: 1671-1681, 2020

65. Daniel M, Bean ZK, Thomas S, Rebecca BA, Amos Folarin LR, Kevin OG and Rosita Zakeri AM: Treatment with ACE-inhibitors is associated with less severe disease with SARS-Covid-19 infection in a multi-site UK acute hospital trust. In: NewsRX LLC, pp612, 2020. 
66. Li J, Wang X, Chen J, Zhang H and Deng A: Association of renin-angiotensin system inhibitors with severity or risk of death in patients with hypertension hospitalized for coronavirus disease 2019 (Covid-19) infection in Wuhan, China. JAMA Cardiol 5: 825-830, 2020.

67. Alexandre J, Cracowski JL, Richard V and Bouhanick B; Drugs, COVID-19' working group of the French Society Of Pharmacology, Therapeutics: Renin-angiotensin-aldosterone system and COVID-19 infection. Ann Endocrinol (Paris) 81: 63-67, 2020.

68. Blaising J, Polyak SJ and Pécheur EI: Arbidol as a broadspectrum antiviral: An update. Antiviral Res 107: 84-94, 2014.

69. Zhu Z, Lu Z, Xu T, Chen C, Yang G, Zha T, Lu J and Xue Y: Arbidol monotherapy is superior to lopinavir/ritonavir in treating COVID-19. J Infect 81: e21-e23, 2020.

70. Wang Z, Yang B, Li Q, Wen L and Zhang R: Clinical features of 69 cases with coronavirus disease 2019 in Wuhan, China. Clin Infect Dis 71: 769-777, 2020.

71. Pécheur EI, Borisevich V, Halfmann P, Morrey JD, Smee DF, Prichard M, Mire CE, Kawaoka Y, Geisbert TW and Polyak SJ The synthetic antiviral drug arbidol inhibits globally prevalent pathogenic viruses. J Virol 90: 3086-3092, 2016.

72. Hulseberg CE, Fénéant L, Szymańska-de Wijs KM, Kessler NP Nelson EA, Shoemaker CJ, Schmaljohn CS, Polyak SJ and White JM: Arbidol and other low-molecular-weight drugs that inhibit lassa and ebola viruses. J Virol 93: e02185-18, 2019.

73. Xu P, Huang J, Fan Z, Huang W, Qi M, Lin X, Song W and Yi L: Arbidol/IFN- $\alpha 2 b$ therapy for patients with corona virus disease 2019: A retrospective multicenter cohort study. Microbes Infect 22: 200-205, 2020.

74. Vincent MJ, Bergeron E, Benjannet S, Erickson BR, Rollin PE, Ksiazek TG, Seidah NG and Nichol ST: Chloroquine is a potent inhibitor of SARS coronavirus infection and spread. Virol J 2: 69, 2005.

75. Yao X, Ye F, Zhang M, Cui C, Huang B, Niu P, Liu X, Zhao L, Dong $\mathrm{E}$, Song $\mathrm{C}$, et al: In vitro antiviral activity and projection of optimized dosing design of hydroxychloroquine for the treatment of severe acute respiratory syndrome coronavirus 2 (SARS-CoV-2). Clin Infect Dis 71: 732-739, 2020.

76. Multicenter collaboration group of Department of Science and Technology of Guangdong Province and Health Commission of Guangdong Province for chloroquine in the treatment of novel coronavirus pneumonia: Expert consensus on chloroquine phosphate for the treatment of novel coronavirus pneumonia. Zhonghua Jie He He Hu Xi Za Zhi 43: 185-188, 2020 (In Chinese)

77. Wang M, Cao R, Zhang L, Yang X, Liu J, Xu M, Shi Z, Hu Z, Zhong W and Xiao G: Remdesivir and chloroquine effectively inhibit the recently emerged novel coronavirus $(2019-\mathrm{nCoV})$ in vitro. Cell Res 30: 269-271, 2020.

78. Gautret P, Lagier JC, Parola P, Hoang VT, Meddeb L, Mailhe M, Doudier B, Courjon J, Giordanengo V, Vieira VE, et al: Hydroxychloroquine and azithromycin as a treatment of COVID-19: Results of an open-label non-randomized clinical trial. Int J Antimicrob Agents 56: 105949, 2020.

79. Looareesuwan S, White NJ, Chanthavanich P, Edwards G, Nicholl DD, Bunch C and Warrell DA: Cardiovascular toxicity and distribution kinetics of intravenous chloroquine. Br J Clin Pharmacol 22: 31-36, 1986.

80. Mackenzie AH: Dose refinements in long-term therapy of rheumatoid arthritis with antimalarials. Am J Med 75: 40-45, 1983.

81. Zhang H, Penninger JM, Li Y, Zhong N and Slutsky AS: Angiotensin-converting enzyme 2 (ACE2) as a SARS-CoV-2 receptor: Molecular mechanisms and potential therapeutic target. Intensive Care Med 46: 586-590, 2020.

82. Cortegiani A, Ingoglia G, Ippolito M, Giarratano A and Einav S: A systematic review on the efficacy and safety of chloroquine for the treatment of COVID-19. J Crit Care 57: 279-283, 2020.

83. Haschke M, Schuster M, Poglitsch M, Loibner H, Salzberg M, Bruggisser M, Penninger J and Krähenbühl S: Pharmacokinetics and pharmacodynamics of recombinant human angiotensin-converting enzyme 2 in healthy human subjects. Clin Pharmacokinet 52: 783-792, 2013.

84. Khan A, Benthin C, Zeno B, Albertson TE, Boyd J, Christie JD, Hall R, Poirier G, Ronco JJ, Tidswell M, et al: A pilot clinical trial of recombinant human angiotensin-converting enzyme 2 in acute respiratory distress syndrome. Crit Care 21: 234, 2017.

85. Monteil V, Kwon H, Prado P, Hagelkrüys A, Wimmer RA, Stahl M, Leopoldi A, Garreta E, Hurtado Del Pozo C, Prosper F, et al: Inhibition of SARS-CoV-2 infections in engineered human tissues using clinical-grade soluble human ACE2. Cell 181: 905-913.e7, 2020.
86. Patel VB, Clarke N, Wang Z, Fan D, Parajuli N, Basu R, Putko B, Kassiri Z, Turner AJ and Oudit GY: Angiotensin II induced proteolytic cleavage of myocardial ACE2 is mediated by TACE/ADAM-17: A positive feedback mechanism in the RAS. J Mol Cell Cardiol 66: 167-176, 2014.

87. Agata J, Ura N, Yoshida H, Shinshi Y, Sasaki H, Hyakkoku M, Taniguchi S and Shimamoto K: Olmesartan is an angiotensin II receptorblocker with an inhibitoryeffect on angiotensin-converting enzyme. Hypertens Res 29: 865-874, 2006.

88. Igase M, Strawn WB, Gallagher PE, Geary RL and Ferrario CM: Angiotensin II AT1 receptors regulate ACE2 and angiotensin-(1-7) expression in the aorta of spontaneously hypertensive rats. Am J Physiol Heart Circ Physiol 289: H1013-H1019, 2005.

89. Ferrario CM, Jessup J, Chappell MC, Averill DB, Brosnihan KB, Tallant EA, Diz DI and Gallagher PE: Effect of angiotensinconverting enzyme inhibition and angiotensin II receptor blockers on cardiac angiotensin-converting enzyme 2. Circulation 111: 2605-2610, 2005.

90. Sukumaran V, Tsuchimochi H, Tatsumi E, Shirai M and Pearson JT: Azilsartan ameliorates diabetic cardiomyopathy in young $\mathrm{db} / \mathrm{db}$ mice through the modulation of ACE-2/ANG 1-7/Mas receptor cascade. Biochem Pharmacol 144: 90-99, 2017.

91. Sukumaran V, Veeraveedu PT, Lakshmanan AP, Gurusamy N, Yamaguchi K, Ma M, Suzuki K, Kodama M and Watanabe K: Olmesartan medoxomil treatment potently improves cardiac myosin-induced dilated cardiomyopathy via the modulation of ACE-2 and ANG 1-7 mas receptor. Free Radic Res 46: 850-860, 2012.

92. Kocks MJ, Lely AT, Boomsma F, de Jong PE and Navis G: Sodium status and angiotensin-converting enzyme inhibition: Effects on plasma angiotensin-(1-7) in healthy man. J Hypertens 23: 597-602, 2005.

93. Ishiyama Y, Gallagher PE, Averill DB, Tallant EA, Brosnihan KB and Ferrario CM: Upregulation of angiotensin-converting enzyme 2 after myocardial infarction by blockade of angiotensin II receptors. Hypertension 43: 970-976, 2004.

94. Tikoo K, Patel G, Kumar S, Karpe PA, Sanghavi M, Malek V and Srinivasan K: Tissue specific up regulation of ACE2 in rabbit model of atherosclerosis by atorvastatin: Role of epigenetic histone modifications. Biochem Pharmacol 93: 343-351, 2015.

95. Shin YH, Min JJ, Lee JH, Kim EH, Kim GE, Kim MH, Lee JJ and Ahn HJ: The effect of fluvastatin on cardiac fibrosis and angiotensin-converting enzyme-2 expression in glucose-controlled diabetic rat hearts. Heart Vessels 32: 618-627, 2017.

96. Imai Y, Kuba K, Rao S, Huan Y, Guo F, Guan B, Yang P, Sarao R, Wada T, Leong-Poi H, et al: Angiotensin-converting enzyme 2 protects from severe acute lung failure. Nature 436: $112-116,2005$

97. Kuba K, Imai Y, Rao S, Jiang C and Penninger JM: Lessons from SARS: Control of acute lung failure by the SARS receptor ACE2. J Mol Med (Berl) 84: 814-820, 2006.

98. Huentelman MJ, Zubcevic J, Hernández Prada JA, Xiao X, Dimitrov DS, Raizada MK and Ostrov DA: Structure-based discovery of a novel angiotensin-converting enzyme 2 inhibitor. Hypertension 44: 903-906, 2004.

99. Lo CS, Liu F, Shi Y, Maachi H, Chenier I, Godin N, Filep JG, Ingelfinger JR, Zhang SL and Chan JS: Dual RAS blockade normalizes angiotensin-converting enzyme-2 expression and prevents hypertension and tubular apoptosis in Akita angiotensinogen-transgenic mice. Am J Physiol Renal Physiol 302. F840-F852, 2012.

100. Lusvarghi S and Bewley CA: Griffithsin: An antiviral lectin with outstanding therapeutic potential. Viruses 8: 296, 2016.

101. O'Keefe BR, Giomarelli B, Barnard DL, Shenoy SR, Chan PK, McMahon JB, Palmer KE, Barnett BW, Meyerholz DK, Wohlford-Lenane CL and McCray PB Jr: Broad-spectrum in vitro activity and in vivo efficacy of the antiviral protein griffithsin against emerging viruses of the family Coronaviridae. J Virol 84: 2511-2521, 2010.

102. Mori T, O'Keefe BR, Sowder RC II, Bringans S, Gardella R, Berg S, Cochran P, Turpin JA, Buckheit RW Jr, McMahon JB and Boyd MR: Isolation and characterization of griffithsin, a novel HIV-inactivating protein, from the red alga Griffithsia sp. J Biol Chem 280: 9345-9353, 2005.

103. Hu H, Li L, Kao RY, Kou B, Wang Z, Zhang L, Zhang H, Hao Z, Tsui WH, Ni A, et al: Screening and identification of linear B-cell epitopes and entry-blocking peptide of severe acute respiratory syndrome (SARS)-associated coronavirus using synthetic overlapping peptide library. J Comb Chem 7: 648-656, 2005. 
104.Han DP, Penn-Nicholson A and Cho MW: Identification of critical determinants on ACE2 for SARS-CoV entry and development of a potent entry inhibitor. Virology 350: 15-25, 2006.

105. Zost SJ, Gilchuk P, Case JB, Binshtein E, Chen RE, Nkolola JP, Schäfer A, Reidy JX, Trivette A, Nargi RS, et al: Potently neutralizing and protective human antibodies against SARS-CoV-2. Nature 584: 443-449, 2020.

106. Huo J, Le Bas A, Ruza RR, Duyvesteyn HME, Mikolajek H, Malinauskas T, Tan TK, Rijal P, Dumoux M, Ward PN, et al: Neutralizing nanobodies bind SARS-CoV-2 spike RBD and block interaction with ACE2. Nat Struct Mol Biol 27: 846-854, 2020.
107. Pinheiro SV, Simões ESA, Sampaio WO, de Paula RD, Mendes EP, Bontempo ED, Pesquero JB, Walther T, Alenina N, Bader M, et al: Nonpeptide AVE 0991 is an angiotensin-(1-7) receptor Mas agonist in the mouse kidney. Hypertension 44: 490-496, 2004.

cc) () $९$ This work is licensed under a Creative Commons EY No ND Attribution-NonCommercial-NoDerivatives 4.0 International (CC BY-NC-ND 4.0) License. 